\title{
Comparison of Body Composition, Eating Habits, Exercise Habits, High Risk Behaviors in a Tri-Racial Group of College Female Athletes
}

\author{
Yi-Tzu Kuo ${ }^{1 *}$, Arlette C Perry ${ }^{2}$, Xuewen Wang ${ }^{3}$, Kevin Jacobs ${ }^{2}$ and Bobby Robertson ${ }^{2}$ \\ ${ }^{1}$ Assistant Professor, USA \\ ${ }^{2}$ Department of Kinesiology and Sport Sciences, USA \\ ${ }^{3}$ Department of Exercise Science, USA
}

*Corresponding author: Yi-Tzu Kuo, Assistant Professor, USA

Submission: 眥 August 22, 2018; Published: 眥 November 09, 2018

\begin{abstract}
There is a lack of information in Hispanic American (HA) athletes regarding body weight concerns, eating habits, exercise habits, and high-risk
Abstract
There is a lack of information in Hispanic American (HA) athletes regarding body weight concerns, eating habits, exercise habits, and high-risk behaviors. The aim of this study was to compare body composition, eating habits, exercise habits, and high-risk behavior in Caucasian American (CA), African American (AA), and HA female athletes. Being Hispanic significantly contributed to the variance in physical characteristics ( $<<0.01$ for all) and variables related to body weight concerns ( $p<0.05$ for all), eating habits ( $p<0.05$ for all), exercise habits ( $<<0.05$ for all), and high-risk behaviors ( $\mathrm{p}<0.05$ for all). These results demonstrated that HA female athletes had significantly different behaviors than CA and AA female athletes.

Keywords: Female athletes; Body composition; Eating habits; Exercise habits; High risk behaviors; Race; Ethnic, Minority
\end{abstract}

\section{Introduction}

In 1970s, a federal anti-discrimination law, Title IX, mandated nondiscrimination and equal opportunity for both sexes in admissions, access, and treatment in all educational programs offered by institutions receiving federal funds. Today, more than ever, girls participating in physical activities are no longer considered "tom boys" but rather role models. Regardless of gender or type of sport involvement, researchers have shown that women significantly benefit from exercise, showing decreased risk of hypertension, type II diabetes, and obesity and its co-morbidities $[1,2]$. Furthermore, improvements in physical fitness derived from sport participation have been associated with longevity (reduction in metabolic risk factors), improved psychological outlook and more positive mood states [3]. Individuals with high levels of physical fitness and activity also possess a more positive self-image [4,5]. Thus, participation in sports and physical activities are found to be positively associated with healthy behaviors and an active lifestyle.

Despite the overwhelming benefits of sports participation and exercise, a higher prevalence of high-risk behaviors have been found in athletes compared to non-athletes [6]. Athletes are reported to consume a significantly greater quantity of alcohol in one sitting compared to their non-athletic peers [7]. Disordered eating constitutes yet another high-risk behavior reported more in athletes than non-athletes [8]. Previous studies have shown a higher incidence of weight and diet concerns in a group of female athletes when compared to non-athletes. A rise in clinical eating disorders and weight concerns that are impacting many female athletes has been documented. Interestingly, racial differences exist in the prevalence of eating disorders with a higher risk of eating disorders among Caucasian-American (CA) and Hispanic-American (HA) female athletes than in African-American (AA) female athletes. Sports participation now includes a wide diversity of ethnic and racial groups. Today, minority athletes comprise more than $57 \%$ of the current collegiate athlete population in the United States (NCAA Student-Athlete Ethnicity Report 2010). Unfortunately, far less information can be found in minority populations, particularly, HA athletes. Given the paucity of information in this growing segment of our population, more research is necessary to gain insight into behavioral issues and concerns of the HA female athlete. The purpose of this study is to examine and compare body composition, body weight concerns, eating/exercise habits, and relative risk behaviors in a diverse racial group of CA, AA, and HA female collegiate athletes.

\section{Participants and Procedure}

A total of 189 athletes completed the modified youth high risk behavior survey, 43.4\% CA, 18.5\% AA, 27.0\% HA, 2.6\% Asian American, and $8.5 \%$ athletes of other races. A total of 21 athletes were not eligible to participate for the study since they were not of CA, AA, or AA racial backgrounds. Anthropometric measures 
including body mass index (BMI), and percent body fat, were evaluated. Participants also completed two paper based and selfadministered questionnaires; an Eating Attitudes Test - 26 (EAT26) and a modification of the Youth High Risk Behavior Survey consisting of 49 items.

\section{Statistical analysis}

Means and standard deviations were determined for each racial group for all physical variables and compared among groups using an analysis of variance (ANOVA). Tukey's post hoc analysis was performed to determine significant differences among racial groups. Descriptive analysis was also performed to examine the distribution of athletes in different racial groups among different sport classifications. Logistic multiple regression analysis was used to determine the independent contribution of physical characteristics and race to four domains: body weight concerns/ behaviors, eating habits/EAT-26, physical activities/habits, and high-risk behaviors. All analyses were performed using SPSS statistical program. A p value of $\leq 0.05$ was accepted as significant.

\section{Methods}

\section{Participants}

This study solicited eligible collegiate female athletes from local Division I Research universities including University of Miami and Florida International University. Female athletes were recruited through advertisement flyer of the study which was posted throughout the athletic department buildings (including locker rooms, athletic training room, meeting rooms, and offices). A total of 189 athletes completed the modified youth high risk behavior survey, 43.4\% CA athletes, 18.5\% AA athletes, 27.0\% HA athletes, 2.6\% Asian American athletes, and $8.5 \%$ athletes of other races. A total of 21 athletes were not eligible to participate for the study since they were not of CA, AA, or AA racial backgrounds, leaving a total of 168 participants. Athletes who were pregnant or who were listed as injured, red -shirted, or on probation at the time of data collection, were not eligible to participate.

\section{Data collection}

Prior to data collection, the study procedure was explained to participants and all subjects were evaluated for BMI, fat distribution, percent body fat, and behavioral measures. The BMI was calculated by using the formula of weight (in pounds) divided by the square of height (in inches), and then multiplied by 703 , [(weight $/$ height $^{2}$ ) x703]. The waist circumference (WAIST) was measured using a spring-tension measuring tape, marking a point on each side of the waist midway between the last palpable rib and the iliac crest (WHO, 1989). The percent body fat was evaluated by measuring the thickness of three skin sites using a Lange skinfold caliper to measure the triceps, anterior thigh, and abdomen. Percent body fat was derived from the formula developed by Jackson \& Pollock (1978). All skinfold measurements were taken by the same investigator. Triceps measurements were taken using a vertical skinfold on the posterior humerus, one half of the distance between the posterior aspect of acromion process of the scapula and the apex of the superior and posterior aspect of olecranon process of the ulnar. The anterior thigh measurements were also taken using a vertical skinfold one half the distance between the midpoint of anterior superior iliac spine anteriorly and midpoint of the superior aspect of the patella. The abdominal measurement was taken using a vertical skinfold pinch one inch laterally from the center of the navel. All three sites were identified and measured according to Wilmore et al. (1969) with intra-observer coefficient of reliability of $98 \%$.

Participants also completed two paper based and selfadministered questionnaires; an Eating Attitudes Test - 26 (EAT26) (Garner et al., 1985) and a modification of the Youth High Risk Behavior Survey consisting of 49 items (CDC, 2005). The EAT-26 has been shown to be a valid and reliable measure of risk of eating disorders (Garner et al., 1985 and CDC 1992). The Youth High Risk Behavior Survey has been widely used since 1990 and shown to be a reliable indicator of relevant health behaviors with Kappa coefficient of $72 \%$ (Brener et al., 1995).

\section{Statistical analysis}

Mean values and standard deviations were determined for each racial group for all physical variables and compared among groups using an analysis of variance (ANOVA). Tukey's post hoc analysis was performed to determine significant differences among racial groups. Descriptive analysis was also performed to examine the distribution of athletes in different racial groups among different sport classifications. Logistic multiple regression analysis was used to determine the independent contribution of physical characteristics and race to four domains: body weight concerns/ behaviors, eating habits/EAT-26, physical activities/habits, and high-risk behaviors. BMI showed a greater contribution to the variance than either WAIST or percent body fat in every one of the four domains examined. Since BMI contributed most to the variance in each of the four domains, it was used as one of the predictors in the model. Race also contributed significantly to the variance in the domains and was examined along with BMI to determine its contribution to the variance in the model. Finally, BMI and race were added together to examine the sum of both in their contribution to the variance in the model. There was no BMI by race interaction for any dependent variables examined in the study. Although the EAT-26 survey is a numerical scale, the scores were categorized into two groups; those scoring below 20 and those scoring 20 and above. These two categories were selected since a score of 20 or above reflect greater risk of developing clinical eating disorders. Linear regression was also performed on the EAT-26 survey since it contained numerical values, and results confirmed the logistic regression analysis. A total of 11 questions from the Youth High Risk Behavior Survey were removed since there was insufficient statistical power to assess predictor variables. This occurred when the cell with cell size fell to less than five. Specifically, three questions were removed from the section assessing body weight concerns and eight questions were removed from the section on high risk behaviors. All analyses were performed using SPSS statistical program (version 18.0 for window; SPSS, Chicago, IL). A $\mathrm{p}$ value of $\leq 0.05$ was accepted as significant. 


\section{Results}

A total of 168 eligible competitive athletes (43.4\% CA athletes, $18.5 \%$ AA athletes, $27.0 \%$ HA athletes) completed the modified youth high risk behavior survey as part of the study. The physical characteristics (means and \pm SD) for the entire sample are shown in Table 1. Although there were no significant differences in BMI, HA athletes weighed significantly less than CA and AA athletes ( $\mathrm{p}<0.05$ and $p<0.001$ respectively) and their height was not different from CA or AA athletes. AA athletes had a lower percent body fat compared to the other groups ( $\mathrm{p}<0.05$ for both). Most athletes participated in the non-aesthetic and non-weight classified sports representing $67 \%, 51 \%$, and $55 \%$ respectively of $\mathrm{CA}, \mathrm{AA}$, and $\mathrm{HA}$ athletes in this study (Table 2).

Table 1: Physical Characteristics (means and standard deviations, SD) of Subjects by Group, Caucasian American (CA), African American (AA), and Hispanic American (HA) (n=168).

\begin{tabular}{|c|c|c|c|c|c|}
\hline \multicolumn{6}{|c|}{ Means \pm SD } \\
\hline & Total $(n=168)$ & CA $(n=82)$ & AA $(n=35)$ & HA $(n=51)$ & $\mathbf{P}^{*}$ \\
\hline Age (years) & $19 \pm 1.4$ & $19 \pm 1.3$ & $19 \pm 1.4$ & $19 \pm 1.5$ & 0.713 \\
\hline Height $(\mathrm{cm})$ & $168.7 \pm 8.9$ & $171.2 \pm 8.9$ & $171.2 \pm 8.1$ & $164.1 \pm 7.4$ & 0 \\
\hline Weight (kg) & $65.6 \pm 12.3$ & $66.5 \pm 12.1$ & $70.2 \pm 14.8$ & $61.0 \pm 9.1$ & 0.002 \\
\hline BMI $\left(\mathrm{kg} / \mathrm{m}^{2}\right)$ & $22.9 \pm 3.2$ & $22.8 \pm 3.2$ & $23.8 \pm 3.9$ & $22.6 \pm 2.7$ & 0.193 \\
\hline$\%$ Body Fat & $26.3 \pm 4.8$ & $27.2 \pm 4.8$ & $24.1 \pm 5.8$ & $26.3 \pm 3.6$ & 0.006 \\
\hline WC (inches) & $30.6 \pm 3.5$ & $31.1 \pm 3.4$ & $30.3 \pm 4.6$ & $30.1 \pm 2.8$ & 0.242 \\
\hline
\end{tabular}

BMI: Body Mass Index [(weight/height2) x 703]; WC: Waist Circumference *: Differences Among Groups Based on ANOVA

Table 2: Racial distribution by sport classifications ( $n=168)$.

\begin{tabular}{|c|c|c|c|c|}
\hline & $\begin{array}{c}\text { Non-aesthetic* Non-weight } \\
\text { classified }\end{array}$ & Non-aesthetic** Speed oriented & $\begin{array}{c}\text { Aesthetic*** Weight } \\
\text { classified }\end{array}$ & 11 \\
\hline Total \\
\hline Caucasian- American & 55 & 16 & 0 & 82 \\
\hline African-American & 18 & 17 & 1 & 35 \\
\hline Hispanic- American & 28 & 22 & 12 & 51 \\
\hline Total & 101 & 55 & 168 \\
\hline
\end{tabular}

*Classifications include: Basketball, Soccer, Tennis, Golf, Mascot, Softball, and Volleyball.

**Classifications include: Swimming and Track and Field.

***Classifications include: Cheerleading, Dance, Diving, and Rowing.

Table 3: Contribution of body mass index (BMI) and race to the prediction of body weight concerns/behaviors for the entire sample $(n=168)$.

\begin{tabular}{|c|c|c|c|}
\hline Question Outcome* & Predictor & $\mathbf{R}^{2}$ & $\mathbf{P} * *$ \\
\hline \multirow{3}{*}{ How do you describe your weight? Underweight, About the right weight, } & BMI & 0.24 & 0 \\
\hline & Race & 0.007 & NS \\
\hline & BMI+ Race & 0.247 & 0 \\
\hline \multirow{3}{*}{ Which of the following are you trying to do about your weight? Lose weight, } & BMI & 0.14 & 0 \\
\hline & Race & 0.023 & NS \\
\hline & BMI+ Race & 0.163 & 0 \\
\hline \multirow{3}{*}{ During the past 30 days, did you exercise to lose weight or keep from gaining weight? } & BMI & 0.11 & 0.001 \\
\hline & Race & 0.046 & 0.04 \\
\hline & BMI+ Race & 0.156 & 0 \\
\hline \multirow{3}{*}{$\begin{array}{l}\text { During the past } 30 \text { days, did you eat less food, calories, or foods low in fat to lose weight to } \\
\text { keep from gaining weight? }\end{array}$} & BMI & 0.075 & 0.004 \\
\hline & Race & 0.05 & 0.046 \\
\hline & BMI + Race & 0.125 & 0.003 \\
\hline
\end{tabular}

*Questions derived from 2005 Youth Risk Behavior Survey

${ }^{* *}$ Logistic regression analysis using BMI, race, and the combination of both. 
In regard to weight concerns or actions taken regarding weight, BMI significantly contributed to how athletes described their weight $(p<0.001)$, actions taken regarding their weight $(p<0.001)$, their intention to lose weight using exercise $(p<0.001)$ and eating practices to control weight $(\mathrm{p}<0.004)$. In each case, as BMI increased, concerns and actions regarding weight increased (Table 3). Race significantly contributed to the use of exercise to lose weight $(\mathrm{p}<0.040)$ and to the habit of eating less food to keep from gaining weight $(\mathrm{p}<0.046)$ as a group (Table 4$)$. With regards to the prediction of eating habits and EAT-26, as BMI increased, the number of days of green salad consumption increased and the scores on the EAT-26 increased. Furthermore, race contributed significantly to the amount of vegetables consumed and the amount of milk consumed in the past 7 days, with HA athletes consuming more vegetables in the last 7 days than AA but not CA athletes $(\mathrm{p}<0.000)$ (Table 5). Results also showed that race contributed significantly to the prediction of whether athletes engaged in physical activities that made them sweat or breathe hard $(\mathrm{p}<0.041$ and $p<0.026$ respectively). Specifically, HA athletes participated in more physical activities that made them sweat and breathe hard in the past 7 days than AA athletes $(\mathrm{p}<0.041)$, whereas CA athletes participated more often in physical activities for 30 minutes that did not make them sweat or breathe compared to HA athletes $(\mathrm{p}<0.026)$.

Table 4: Contribution of body mass index (BMI), and race to the prediction of eating habits and the Eating Attitudes Test-26 (EAT-26) for the entire sample $(n=168)$.

\begin{tabular}{|c|c|c|c|}
\hline Question Outcome* & Predictor & $\mathbf{R}^{2}$ & $\mathbf{P}^{* *}$ \\
\hline \multirow{3}{*}{$\begin{array}{c}\text { During the past } 7 \text { days, how many times did you drink } 100 \% \text { fruit juice such as orange juice, } \\
\text { apple juice, or grape juice? }\end{array}$} & BMI & 0.006 & NS \\
\hline & Race & 0.006 & NS \\
\hline & $\mathrm{BMI}+$ Race & 0.012 & NS \\
\hline \multirow{3}{*}{ During the past 7 days, how many times did you eat fruit? (not counting fruit juice) } & BMI & 0.007 & NS \\
\hline & Race & 0.063 & NS \\
\hline & BMI + Race & 0.07 & NS \\
\hline \multirow{3}{*}{ During the past 7 days, how many times did you eat green salad? } & BMI & 0.044 & 0.014 \\
\hline & Race & 0.088 & NS \\
\hline & BMI + Race & 0.126 & 0.007 \\
\hline \multirow{3}{*}{$\begin{array}{l}\text { During the past } 7 \text { days, how many times did you eat other vegetables? (not counting green } \\
\text { salad) }\end{array}$} & BMI & 0.021 & NS \\
\hline & Race & 0.094 & $\neq 0.00$ \\
\hline & BMI + Race & 0.115 & NS \\
\hline \multirow{3}{*}{ During the past 7 days, how may glasses of milk did you drink? } & BMI & 0 & NS \\
\hline & Race & 0.038 & $\dagger 0.041$ \\
\hline & BMI + Race & 0.038 & NS \\
\hline \multirow{3}{*}{ EAT-26 Behavior Survey } & BMI & 0.137 & 0 \\
\hline & Race & 0.001 & NS \\
\hline & BMI + Race & 0.138 & NS \\
\hline
\end{tabular}

*Questions derived from 2005 Youth Risk Behavior Survey

**Logistic regression analysis using BMI, race, and the combination of both

$\dagger$ Significant difference between CA and HA athletes $(\mathrm{p}<0.05)$

$\ddagger$ Significant difference between HA and AA athletes $(\mathrm{p}<0.01)$

Table 5: Contribution of body mass index (BMI) and race to the prediction of physical activities/habits for the entire sample $(n=168)$.

\begin{tabular}{|c|c|c|c|}
\hline Question Outcome* & Predictor & $\mathbf{R}^{2}$ & $\mathbf{P}^{* *}$ \\
\hline \multirow{3}{*}{$\begin{array}{l}\text { On how many of the past } 7 \text { days did you exercise or participate in physical activities for at } \\
\text { least } 20 \text { minutes that made you sweat and breathe hard? }\end{array}$} & BMI & 0.008 & NS \\
\hline & Race & 0.048 & $\neq 0.041$ \\
\hline & BMI + Race & 0.056 & NS \\
\hline \multirow{3}{*}{$\begin{array}{l}\text { On how many of the past } 7 \text { days, did you participate in physical activities for at least } 30 \text { min- } \\
\text { utes that did not make you sweat or breathe hard? }\end{array}$} & BMI & 0.012 & NS \\
\hline & Race & 0.063 & $\dagger 0.026$ \\
\hline & BMI + Race & 0.075 & NS \\
\hline
\end{tabular}


On how many of the past 7 days, did you do exercise to strengthen or tone your muscles?

On an average school day, how many hours do you watch TV?

\begin{tabular}{|c|c|c|}
\hline BMI & 0.002 & NS \\
\hline Race & 0 & NS \\
\hline BMI + Race & 0.002 & NS \\
\hline BMI & 0.062 & 0.002 \\
\hline Race & 0.017 & NS \\
\hline BMI + Race & 0.079 & 0.004 \\
\hline
\end{tabular}

*Questions derived from 2005 Youth Risk Behavior Survey

**Logistic regression analysis using BMI, race, and the combination of both

$\dagger$ Significant difference between CA and HA athletes $(\mathrm{p}<0.05)$

$\ddagger$ Significant difference between HA and AA athletes $(\mathrm{p}<0.05)$

The higher the BMI, the more likely athletes were found engaging in high risk behaviors such as riding in a car driven by someone who had been drinking alcohol in the past 30 days $(\mathrm{p}<0.040)$, spending time consuming alcohol on or off campus property in the past 30 days $(\mathrm{p}<0.014)$, and carrying a weapon in the past 30 days $(\mathrm{p}<0.008)$ (Table 6$)$. Results also showed greater

BMI were associated with greater number of times using marijuana in a lifetime $(\mathrm{p}<0.046)$ and the number of sexual partners in a period of 3 months $(\mathrm{p}<0.003)$. Differences in the number of sexual partners remained significant among groups when race was added, specifically in HA athletes, indicating that both a higher BMI and being Hispanic significantly contributed to this high-risk behavior.

Table 6: Contribution of body mass index (BMI) and race to the prediction of high risk behaviors for the entire sample $(n=168)$.

\begin{tabular}{|c|c|c|c|}
\hline Question Outcome* & Predictor & $\mathbf{R}^{2}$ & $\mathbf{P}^{* *}$ \\
\hline \multirow{3}{*}{ When you rode a bicycle during the past 12 months, how often did you wear a helmet? } & BMI & 0.009 & NS \\
\hline & Race & 0.004 & NS \\
\hline & $\mathrm{BMI}+$ Race & 0.013 & NS \\
\hline \multirow{3}{*}{ How often do you wear a seat belt when riding in a car driven by someone else? } & BMI & 0.011 & NS \\
\hline & Race & 0.011 & NS \\
\hline & $\mathrm{BMI}+$ Race & 0.022 & NS \\
\hline \multirow{3}{*}{$\begin{array}{c}\text { During the past } 30 \text { days, how many times did you ride in a car or other vehicle driven by } \\
\text { someone who had been drinking alcohol? }\end{array}$} & BMI & 0.031 & 0.04 \\
\hline & Race & -0.018 & NS \\
\hline & BMI + Race & 0.013 & NS \\
\hline \multirow{3}{*}{$\begin{array}{c}\text { During the past } 30 \text { days, how many times did you drive a car or other vehicle when you had } \\
\text { been drinking alcohol? }\end{array}$} & BMI & 0.008 & NS \\
\hline & Race & 0.026 & NS \\
\hline & BMI + Race & 0.034 & NS \\
\hline \multirow{3}{*}{$\begin{array}{l}\text { During the past } 30 \text { days, on how many days did you carry a weapon such as a gun, knife, or } \\
\text { club? }\end{array}$} & BMI & 0.123 & 0.008 \\
\hline & Race & 0.022 & NS \\
\hline & BMI + Race & 0.145 & 0.016 \\
\hline \multirow{3}{*}{$\begin{array}{c}\text { During the past } 12 \text { months, how many times were you in a physical fight on or off school } \\
\text { property? }\end{array}$} & BMI & 0.034 & NS \\
\hline & Race & 0.039 & NS \\
\hline & BMI + Race & 0.073 & NS \\
\hline \multirow{3}{*}{ During the past 12 months, did anyone ever hit, slap, or physically hurt you on purpose? } & BMI & 0.01 & NS \\
\hline & Race & 0.019 & NS \\
\hline & $\mathrm{BMI}+$ Race & 0.029 & NS \\
\hline \multirow{3}{*}{ Have you ever tried cigarette smoking, even one or two puffs? } & BMI & 0.017 & NS \\
\hline & Race & 0.054 & NS \\
\hline & $\mathrm{BMI}+$ Race & 0.071 & NS \\
\hline \multirow{3}{*}{ How old were you when you smoked a whole cigarette for the first time? } & BMI & 0.019 & NS \\
\hline & Race & 0.075 & $\neq 0.028$ \\
\hline & $\mathrm{BMI}+$ Race & 0.094 & NS \\
\hline
\end{tabular}




\begin{tabular}{|c|c|c|c|}
\hline \multirow{3}{*}{ During your life, on how many days have you had at least one drink of alcohol? } & BMI & 0.004 & NS \\
\hline & Race & 0.055 & NS \\
\hline & $\mathrm{BMI}+$ Race & 0.059 & NS \\
\hline \multirow{3}{*}{ How old were you when you had your first drink of alcohol other than a few sips? } & BMI & 0 & NS \\
\hline & Race & 0.019 & NS \\
\hline & BMI + Race & 0.019 & NS \\
\hline \multirow{3}{*}{$\begin{array}{l}\text { During the past } 30 \text { days, on how many days did you have at least one drink of alcohol either } \\
\text { on or off school property? }\end{array}$} & BMI & 0.042 & 0.014 \\
\hline & Race & 0.006 & NS \\
\hline & $\mathrm{BMI}+$ Race & 0.048 & 0.011 \\
\hline \multirow{3}{*}{ During your life, how many times have you used marijuana? } & BMI & 0.025 & 0.046 \\
\hline & Race & 0.015 & NS \\
\hline & BMI + Race & 0.04 & 0.045 \\
\hline \multirow{3}{*}{ How old were you when you tried marijuana for the first time? } & BMI & 0.025 & NS \\
\hline & Race & 0.013 & NS \\
\hline & BMI + Race & 0.038 & NS \\
\hline \multirow{3}{*}{ Have you ever had sexual intercourse? } & BMI & 0.002 & NS \\
\hline & Race & 0.013 & NS \\
\hline & BMI + Race & 0.015 & NS \\
\hline \multirow{3}{*}{ During the past 3 months, with how many people did you have sexual intercourse? } & BMI & 0.101 & 0.003 \\
\hline & Race & 0.063 & $\dagger 0.028$ \\
\hline & BMI + Race & 0.164 & 0.003 \\
\hline
\end{tabular}

*Questions derived from 2005 Youth Risk Behavior Survey

**Logistic regression analysis using BMI, race, and the combination of both

$\dagger$ Significant difference between CA and HA athletes $(\mathrm{p}<0.05)$

$\ddagger$ Significant difference between HA and AA athletes $(p<0.05)$

\section{Discussion}

Past research has indicated a higher prevalence of eating disorders, reduced percent body fat, and more aberrant eating habits among athletes compared to the general population. Unfortunately, previous studies have focused upon CA and/or AA athletes and very few studies to date have examined HA athletes. Although no differences in BMI were found among our competitive athletes, a lower percent body fat was found among AA athletes. Lower body fat percentages at similar BMI levels have been demonstrated in non-athletic adolescent female populations. Thus, female athletes are like non-athletic populations with regard to BMI and percent body fat, however, our study shows that in athletes, those with higher BMI, the greater the weight concerns and preoccupation with weight. Interestingly, our study also demonstrated that the higher the BMI, the more likely the athlete is to exercise to keep from gaining weight. Thus, our findings support the same alarming reoccurring trend in collegiate athletes as in high school nonathletes of weight concern/preoccupation with increasing BMI levels and the use of exercise to keep from gaining weight.

The increased risk of developing disordered eating in athletes compared to non-athletes has been demonstrated in previous studies. More specifically, low body fat in competitive sports demanding speed as well as sports requiring aesthetic appeal may be advantageous while at the same time posing greater risk for developing unhealthy eating behaviors. Our study showed that the higher the BMI, the greater the food consumption, and the higher the EAT-26 scores across the entire sample. Although only $4 \%$ of our athletes had EAT-26 scores associated with clinical risk for eating disorders and only $18 \%$ of athletes had BMI's outside healthy range $\left(18.5 \mathrm{~kg} / \mathrm{m}^{2}\right.$ to $\left.24.9 \mathrm{~kg} / \mathrm{m}^{2}\right)$, our findings confirmed that increases in BMI were related to increased food consumption and greater risk of eating disorders. Thus, even among competitive athletes who, for the most part fall within a normal BMI range, the positive relationship between BMI levels and EAT-26 scores, remained significant.

Collegiate athletes are constantly under pressure to perform well due to scholarship commitments, pressure from coaches, or simply the passion to excel in their sport. As a result, the pressure of today's sports has put many young competitors in situations which often contribute to extreme diet, exercise, or weight issues. Similar to our findings, Colabianchi reported that non-athletic adolescent HA girls were mostly likely to exercise with the purpose of losing weight than CA or AA adolescent girls. The combination of peer pressure and cultural background in HA girls may account for their feeling more pressure to perform well or look a certain way. 
Independent of obesity issues, there is a strong relationship between high risk behaviors and morbidity and mortality in young adults. Hingson estimated that in 2001, nearly 600,000 college students were injured due to alcohol-related injuries. In the present study, the higher the BMI, the more likely the athlete would ride in a car with someone who had been drinking alcohol or carry a weapon themselves in the last 30 days. BMI was also associated with drinking more alcoholic beverages and using marijuana in the past 30 days. Previous studies have also shown that alcohol use is positively associated with increased BMI in non-athletic adolescents. ${ }^{30,31}$ The present study reaffirmed and extended the relationship between BMI and alcohol consumption to occur among competitive collegiate athletes as well.

Rhea $^{8}$ suggested that HA adolescent girls are more likely to adopt societal values about attractiveness and thinness than CA girls. This can lead to more aberrant behaviors and more extreme practices in order to fit into mainstream society. Our study confirms this in that HA athletes were more likely to smoke cigarettes at a younger age than AA athletes and more likely to have a greater number of sexual partners than CA athletes. Findings also showed that both a higher BMI and being Hispanic were significantly related to the increased number of sexual partners within the last three months. These results highlight the fact that high BMI levels maybe associated with high risk behaviors in collegiate athletes, particularly HA athletes.

There are several limitations that need to be addressed in this study. Our study used a self-administered high-risk behavior survey and EAT-26 questionnaire which may result in less accurate results and under-reporting. The small sample size may limit the power of the results. Furthermore, the majority of CA, AA, and HA athletes participated in non-aesthetic and non-weight classified sports. Therefore, sports such as gymnastics, diving, cheerleading were not included and may have generated different results. Finally, acculturation, self-esteem, and peer acceptance were not measured in the present study and this too may have contributed valuable information given our sample demographics and findings.
Our results provided evidence that BMI is related to behavioral characteristics encompassing body weight concerns, eating habits, and risk taking in competitive female athletes. This is like what has been found in non-athletic adolescents and young adults. However, athletes were found to use exercise as mean to control their BMI and weight levels. Our study showed the HA athletes demonstrated significantly different behavioral characteristics than CA and AA athletes highlighting the need for more research in this growing segment of our population's minority athletes. Our study represents an important first step in the recognition and identification of relevant behavioral differences in competitive collegiate female athletes with different racial backgrounds. It is imperative to develop a pre-participation physical examination that includes a more effective screening tool for recognizing athletes at higher risk for developing unsafe and high-risk behaviors.

\section{References}

1. World Health Organization (1989) Measuring obesity: classification and distribution of anthropometric data. WHO, Copenhagen, Denmark.

2. Jackson AS, Pollock ML (1978) Generalized equations for predicting body density of men. Br J Nutr 40(3): 497-504.

3. Wilmore JHJ, Behnke ARA (1969) An anthropometric estimation of body density and lean body weight in young men. J Appl Physiol 27(1): 25-31.

4. Garner DM, Rockert W, Olmstead MP, Johnson C, Coscina DV (1985) Psycho-educational principles in the treatment of bulimia and anorexia nervosa. In: Garner DM, Garfinkel PE (Eds.), Handbook of psychotherapy for anorexia nervosa and bulimia. Guilford, New York, USA.

5. Centers for Disease Control and Prevention (2005) Youth Risk Behavior Surveillance-United States.

6. Brener ND, Kann L, Mcmanus T, Kinchen SA, Sundberg EC, et al. (2002) Reliability of the 1999 youth risk behavior survey questionnaire. J Adolesc Health 31(4): 336-342.

7. SPSS Inc (2009) PASW statistics for windows, Version 18.0. SPSS Inc, Chicago, USA.

8. Irick E (2011) NCAA race and gender demographics, National Collegiate Athletics Association, Indianapolis, USA.
Creative Commons Attribution 4.0 International License

For possible submissions Click Here

\section{Submit Article}

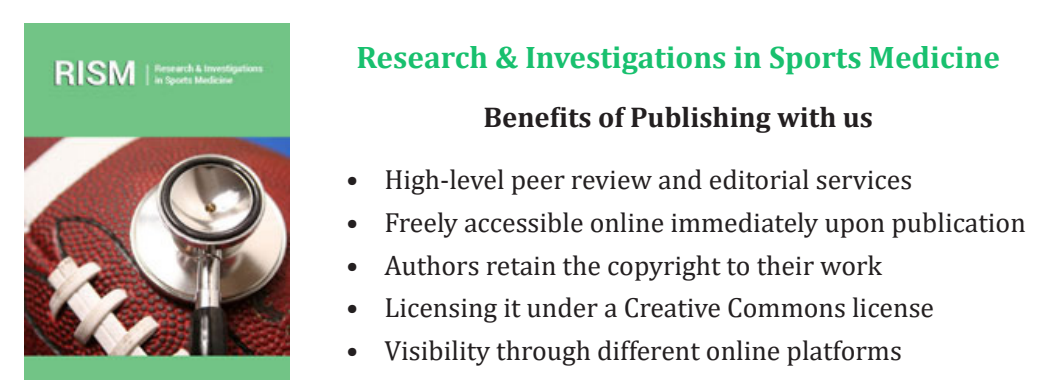

